\title{
Tibet studies in Australia, Hong Kong and Singapore
}

\author{
Colin Mackerras* \\ Griffith Asia Institute, Griffith University, Queensland, Australia
}

\begin{abstract}
This paper takes up the study of Tibet in Australia, Hong Kong and Singapore. Tibet studies are defined through scholars working in universities in the specified countries/regions who have published works in which the Tibetans and the Tibetan areas of China are focal. The methodology is to analyse selected published works on Tibet as well as to interview selected scholars. The paper attempts to draw some characteristics of Tibet studies in the regions or countries specified, defined according to factors such as discipline, priority of language, area of interest, approach or political stand. It reaches no grand conclusions, but finds that the spectrum of Tibet studies in the places considered is fairly wide and, though not comparable with several other countries, the value is quite high in terms of quantity and quality.
\end{abstract}

Keywords: Tibet studies, Australia, Hong Kong, Singapore

\section{Introduction, scope}

This paper takes up Tibet studies in Australia, Hong Kong and Singapore. The definition of Tibet studies in those places is the study of Tibetan people and/or of the Tibetan areas of China undertaken by scholars holding paid positions on the staff of universities in the specified places at the time this article was prepared, namely the late months of 2009 and throughout much of 2010. For reasons of space, these scholars do not include postdoctoral research students. The Tibetan people studied refer mainly but certainly not exclusively to those living in territories recognized by the present international community as part of China.

*Email: c.mackerras@griffith.edu.au 
The emphasis of the Tibet studies themselves is on the twentieth and twenty-first centuries, but does not exclude earlier periods altogether. The disciplinary focus is on history, religious studies, anthropology, language studies, political economy, law, education studies, international relations, and philosophy.

The methodology is mainly two-fold. Firstly, I have tried to analyse some of the main published works of the scholars covered, especially recent ones and those that came out while they were working in the places of interest in this article. Secondly, I have interviewed several main relevant scholars, specifically John Powers of the Australian National University (11 December 2009), Susette Cooke of the University of Technology, Sydney (9 October 2009), Ben Hillman of the Australian National University (10 October 2009), Barry Sautman of the University of Science and Technology of Hong Kong (16 October 2009), and Gerard Postiglione of the University of Hong Kong (13 March 2010). On 23 November 2009 I attended a workshop organized by He Baogang of Deakin University and held at Deakin University in Melbourne, with a range of other participants, including Mark Stephenson of Victoria University in Melbourne and Gillian Tan, who has just finished her PhD at the University of Melbourne but now gone to work in Paris. Both of these scholars are anthropologists who have worked directly on Tibet. Another participant was James Leibold of La Trobe University, a historian who has published in Chinese minority studies in which Tibet is relevant. All interviews were wide-ranging and fairly unstructured. In other words, I think it important to get interviewees to talk about what is important to them. The workshop was structured around several of He Baogang's works, but was actually quite free-ranging in practice and gave me many insights into the work on Tibet in Australia. On the other hand, because of space 
constrictions it has not been possible to include more than a small amount of material from any particular scholar. Inevitably, the judgement on what is included is my own, and based on such factors as fit with the scope of the article, as defined above.

For the purposes of the present paper, I divide Tibet studies into two distinct categories. The first is Tibetology, which comes to Tibet studies through Tibetan language and an interest in Tibetan culture, religion and history, as opposed to or at least distinct from China studies. Such scholars are likely to emphasize knowledge of Tibetan rather than Chinese language. They are likely to know a good deal about Tibetan culture, but not necessarily Chinese. They are likely to have good contacts in Dharamsala, but may not very good ones in China, or even not have visited China much or at all.

The second category consists of those who have come to Tibet studies through the study of China. Most of these know Chinese and specialize in China studies, but may not know Tibetan language very well or even at all, and have few or no contacts in Dharamsala but probably some or many contacts in China, and in particular the Tibetan areas of China. Although there is no clear-cut distinction over political position, the strong tendency is for Tibetologists to be much more strongly in support of the Tibetan-government-in-exile (TGIE) than those who approach Tibet through China studies. Although there is a strong tendency for scholars to be critical of China's position and policies in Tibet, support for it comes almost entirely from the latter group, that is, those who approach Tibet through China studies. 


\section{Australia}

Although the coverage here is entirely about scholarly work, some brief background on the place of Tibet in Australia's relations with China and Australian images of Tibet will be useful. As in other countries visits by the Dalai Lama have to some extent impacted on relations with China. The Dalai Lama came to Australia in 1992, 1996, 2002, 2007 and 2009. The first time was under the prime ministership of Australian Labor Party (ALP) leader Paul Keating (1991-96), the second to fourth under that of the conservative Coalition's John Howard (1996-2007), and the fifth under the ALP leader's Kevin Rudd (20072010). The first visit excited hardly any interest among the Chinese authorities. This was despite the fact that both Keating and his Minister of Foreign Affairs Gareth Evans met the Dalai Lama, who persuaded them to allow the establishment of a Tibet Information Office, a highly political body representing the Dalai Lama's interests. The second visit was part of a crisis in China-Australia relations that occurred at the beginning of the Howard period. Both Howard and Foreign Minister Alexander Downer met the Dalai Lama to China's great and strongly expressed annoyance. By the time of the third visit, both Howard and Downer had succumbed much more strongly to China's influence and were in any case out of the country, thus not repeating meetings with the Dalai Lama. ${ }^{1}$ During his 2007 visit, both Prime Minister Howard and the then leader of the Opposition Kevin Rudd met the Dalai Lama. Although the Chinese protested, the country was moving towards election mode, with both men trying to curry favour with the electorate as their top priority. Rudd was careful to specify that his meeting with the Dalai Lama was with a religious, not political, leader. During the Dalai

\footnotetext{
${ }^{1}$ See Mackerras, ‘The Australia-China Relationship’, 24.
} 
Lama’s late-2009 visit, Kevin Rudd did not meet with him, while the just-chosen Leader of the Opposition Tony Abbott not only made a point of meeting him, but also criticized Rudd for not doing so.

This brings me to the next point, which is that public opinion in Australia tends strongly to side with the Dalai Lama against the Chinese over the Tibet issue. The Greens leader Senator Bob Brown is quite vociferous in his support for the Dalai Lama and his autonomy proposals and strongly hostile to the Chinese for their perceived infringements of human rights in Tibet. There are members of the ALP that are strongly supportive of the Dalai Lama. Journalists tend to turn to the pro-Dalai Lama Australia-Tibet Council for media comment, not to the Chinese or to the pro-Chinese Australia-China Friendship Society.

There are actually quite a few scholars in Australia working on Tibet in one way or another, if one includes not only those holding a formal academic position, but doctoral students and those working in adjunct or other unpaid functions in universities. At the 2008 conference of the Asian Studies Association of Australia held in Melbourne, there was a full panel on Tibet. One of the papers, by then PhD student Gillian Tan in Anthropology at the University of Melbourne, took up some issues of social change in Eastern Tibet, while another was by David Templeman and concerned the role of Buddhism in the early-seventeenth-century civil war in Tibet. Having finished his PhD at Monash University, Melbourne, Templeman now works there in an adjunct capacity. He has a long-standing and deep interest in and knowledge of Tibetan culture, religion and history, and knows Tibetan well, but has never been to Tibet. His work has been largely in the translation and editing of Tibetan hagiographies, but undertaken due to enthusiasm rather than as part of work at a university. His $\mathrm{PhD}$ came at the end of 
his career. Tan and Templeman are among students of Tibet who, despite excellent work, do not fit closely enough under the ambit of this paper, as defined above, for full consideration.

Although there are PhD students undertaking research work on Tibet and Tibetans, there are no Tibetan language courses taught at universities in Australia. During our interview, John Powers told me that any students wanting to learn Tibetan language had to go elsewhere to undertake immersion courses in the language. On the other hand, he runs a course on Buddhism, a large section about Tibetan Buddhism, for which he gets fifty to sixty students each year. And as for $\mathrm{PhD}$ students, there are so many applicants that he has to turn most of them away. At the University of Tasmania's School of Philosophy there are several courses on Buddhism, including Tibetan Buddhism, which are taught by Dr Sonam Thakchoe. A graduate of the Central Institute of Higher Tibetan Studies, Sarnath, Varanasi, India, he is the primary organizer of an exchange programme in Buddhist studies, which enables Tibetans from India to visit as colleagues, teachers or students, and for its own students to study at the Tibetan universities in India, especially the Central Institute of Higher Tibetan Studies. The Dalai Lama has visited the University of Tasmania more than once, including towards the end of 2009.

\section{Tibetologists in Australia}

Probably the most prolific scholar working in an Australian university on Tibet is John Powers of the Australian National University. Specialist on Indian philosophy and author of several books and numerous articles on Tibetan history, religion and culture, he is one of only few scholars considered in these pages in 
knowing Tibetan language well and also having some familiarity with classical Chinese. In this sense he is a real Tibetologist according to the definition adopted above.

His main book on Tibetan Buddhism is entitled Introduction to Tibetan Buddhism, first published by Snow Lion Publications in Ithaca, New York, in 1995. Divided into four parts, covering 'the Indian background', 'Tibetan history and culture', 'Tibetan Buddhist doctrines and practices' and 'the schools of Tibetan Buddhism', it takes a broad-ranging approach to its subject and established its author as a leading authority not only on Tibetan religion but culture more generally. At the time it was written Powers was still working in the U.S.

A book highly relevant to this article is History as Propaganda, Tibetan Exiles Versus the People’s Republic of China, Oxford University Press, 2004. This work takes views put forward by Tibetan exiles and PRC historians and contrasts them, showing the entirely different assumptions, analyses and conclusions about Tibetan nationhood. In addition, Powers selects some Western scholars working on Tibet, categorizing some of them as predominantly proChinese (for instance, Israel Epstein, A. Tom Grunfeld, and Melvyn Goldstein) or pro-Tibetan (examples including Robert Thurman, Warren Smith and Hugh Richardson). Despite putting him on China’s side, Powers seems most impressed with Goldstein, whose A History of Modern Tibet he describes as 'a massive work that in my opinion is the most balanced treatment of modern Tibetan history'. ${ }^{2}$

Powers is quite right in his suggestion that interpretations of history are integral to national self-identity and its politics. He rightly sees history used as

\footnotetext{
${ }^{2}$ Powers, History as Propaganda, 17.
} 
propaganda both by historians representing both China and the Tibetan government-in-exile (TGIE). He puts it well in saying: 'Much of the discourse resembles a political rally in which competing factions yell slogans at each other from behind barriers that physically separate them'.3

Powers has a grant from the Australian Research Council for a project on contemporary Tibetan Buddhism. By the end of 2009 he had undertaken most of the research for the book, which will be published by the Harvard University Press, and even begun writing it. The disturbances of March 2008 and their causes will loom large in his coverage. His research so far has isolated the patriotic education campaigns as the chief issue causing the disturbances, at least as far as religion is concerned. 'Tibetans just want to be left alone', he told me during our interview.

A Tibetologist whose focus is on Tibetan Buddhist philosophy is Sonam Thakchoe. Initially trained at the Central Institute of Higher Tibetan Studies in the history of Indo-Tibetan Buddhist philosophy, he gained his $\mathrm{PhD}$ at the University of Tasmania in 2002 and has worked there since then. His main single publication is a monograph on two major figures in medieval Tibetan Buddhist philosophy entitled The Two Truths Debate: Tsongkhapa and Gorampa on the Middle Way. ${ }^{4}$ He has also written several articles on similar themes in Tibetan Buddhist philosophy. ${ }^{5}$

A scholar whom Powers recommended to me as a real Tibetologist is Mark Stevenson, a senior lecturer in Victoria University in Melbourne. Since 1990 he

\footnotetext{
${ }^{3}$ Ibid., 159.

${ }^{4}$ Tsongkhapa (1357-1423) was the most important figure in medieval Tibetan Buddhism and founder of the dominant Gelugpa order; his image is still found in Tibetan Buddhist monasteries of that order. Gorampa (1429-89) was also a distinguished Tibetan monk-scholar.

${ }^{5}$ Thakchoe, 'Status of Conventional Truth in Tsong khapa's Mādhyamika Philosophy' and Thakchoe, 'Transcendental Knowledge in Tibetan Mādhyamika Epistempology'.
} 
has undertaken extensive anthropological fieldwork in Huangnan Tibetan Autonomous Prefecture, Qinghai Province or to Tibetans Amdo. Especially interested in the cultural politics of art, he has carried out pioneering work on painters in the Huangnan capital Rebkong (known to the Chinese as Tongren). He is now working on the social significance of architectural features in Amdo, both in terms of Tibetan kinship and the role of Chinese artisans. His main publication in the field of Tibet studies is Many Paths: Searching for Old Tibet in New China, which came out in 2005. It is a detailed diary of his experiences in the Tibetan areas of China, and especially Rebkong, from 1989 to 1992, with some minor consideration of later visits. Covering a range of historical but especially contemporary issues, it is not thickly documented, but does contain much thoughtful insight into the ways Tibetan culture has fared under the CCP. Unfortunately, its publisher is comparatively unknown and this book has not received the attention and distribution it deserves.

\section{China Scholars with Tibet Specialism}

In one sense, Stevenson straddles both categories of Tibet scholars, since he has substantial expertise not only in Tibet but also in China studies. In particular, he has worked on gender issues in the Qing dynasty, especially the social role of actors in the rise of the Jingju (Peking Opera). He forms a link to the contemporary political world in which the study of Tibet becomes a subcategory of that of China.

In this area the pre-eminent scholar in Australia is currently Professor He Baogang of Deakin University. As Powers’s work raises important theoretical issues relating to history, so He's is highly infused theoretically from the point of 
view of political science. Unlike Powers, he does not know Tibetan and has so far produced no books exclusively about Tibet or Tibetan issues. However, his writing is completely bilingual (English and Chinese) and he has authored and edited many books on democracy in China in both languages. ${ }^{6}$ Among the many questions his work covers are those relating to ethnic minorities generally, including as these affect China. And one relevant issue is the impact of Confucianism on China's policies towards minorities, including the Tibet question. ${ }^{7}$ His work specifically on Tibet deals with some extremely important contemporary matters involving understanding both of contemporary Chinese government and non-government views, as well as of views among the Tibetan political class.

A good example of his work on Tibet is a book-chapter that came out in 2006. It concerns the Dalai Lama's proposals for autonomy, and the potential for negotiating with the Chinese over them. He believes the proposals unacceptable to China, the first reason being that 'Beijing thinks that the acceptance of the proposal would create an internal boundary and an "independent kingdom,” which would eventually lead to Tibet's full independence'. ${ }^{8}$ The preceding year, He published an article on a similar topic jointly with Barry Sautman. Their belief at the time was that the Dalai Lama had made significant concessions in some areas of his proposals on 'genuine autonomy' in the hope of pursuing negotiations with China to success. The two authors do not rule out a solution, but believe both

\footnotetext{
${ }^{6}$ For example, see He, The Democratic Implications of Civil Society in China, Rural Democracy in China and The Democratization of China.

${ }^{7}$ For instance, see He, 'Minority Rights with Chinese Characteristics'.

${ }^{8} \mathrm{He}$, 'The Dalai Lama’s Autonomy Proposal', 80.
} 
sides will need to give further ground, with the Dalai Lama’s 2005 position being unacceptable to China, even with the concessions recently made. ${ }^{9}$

A young scholar working at the Australian National University is Dr Ben Hillman, who teaches on comparative government and democracy and has expertise not only in China but also in Indonesia. His PhD thesis is based on extensive fieldwork in the Diqing Tibetan Autonomous Prefecture in Yunnan Province and Hillman intends eventually to publish it. Up to now, Hillman’s publications on the Tibetans include a major scholarly article on monasticism in Diqing Prefecture and several shorter pieces, including a highly informed comment on the lead-up to and causes of the March 2008 riots. ${ }^{10}$ Although the volume of his publications on Tibet is still not large, he is a scholar of great potential, and is likely to publish a good deal in the coming years. His having worked on regional autonomy and ethnic politics not only in China but also in Indonesia gives him capacity to bring a comparative perspective to the study of the Tibet situation.

Susette Cooke is a member of the China Research Centre at the University of Technology, Sydney, her work on Tibet and the Tibetans including some general and wide-ranging studies. ${ }^{11}$ She has also carried out research on the social consequences of migration and economic development in central Lhasa. ${ }^{12}$ Although not engaged in major new work on Tibet, she will continue work on ethnic issues through a significant grant she won at the end of 2009 to investigate non-Tibetan minorities in mixed ethnocultural areas of Qinghai and Yunnan.

\footnotetext{
${ }^{9}$ He and Sautman, 'The Politics of the Dalai Lama's New Initiative for Autonomy'.

${ }^{10}$ See Hillman, 'Monasticism and the Local State' and 'Money Can't Buy Tibetans' Love'.

${ }^{11}$ For example, see Cooke, 'Merging Tibetan Culture'.

12 See Cooke, 'Central Lhasa and Migration'.
} 
Cooke is alone in giving detailed treatment to the issue of gender, and especially in connection with Buddhism and Tibetan nationality. Her book chapter on Tibetan nuns takes up the 'profound ideological and psychological incompatibilities between the nuns and the Chinese state, rooted in culture, history and contemporary political imperatives' ${ }^{13}$ It is an important contribution to issues of gender, religion and ethnic identity, taking up also the effect of patriotic education campaigns on nuns. During my interview with Cooke, she stressed the impossibility that nuns would denounce the Dalai Lama, as patriotic education campaigns required them to do, since that was tantamount to renouncing the religion to which, as nuns, they had committed their lives. We saw the injurious impact of the patriotic education campaigns also in connection with the work Powers is currently undertaking.

My own work on Tibet developed entirely through an interest in Chinese history and China's ethnic minorities. I have written several books and numerous book chapters and articles on the minorities, the Tibetans looming large in most of them, but the focus being on ethnic issues in general, not just the Tibetans. ${ }^{14} \mathrm{My}$ only extended piece exclusively about Tibet was written for and at the request of the UNHCR. Never printed, it was published on the UNHCR's website in 2005 and took the form of a political and religious historical treatment of the Tibetans under the People’s Republic, with some focus on human rights, gender and refugee issues. $^{15}$

\footnotetext{
${ }^{13}$ Cooke, “'To Struggle for Freedom”', 119. Another interesting article by Cooke is 'Becoming and Unbecoming Tu', which also deals with the issue of ethnic identity. However, because it is not about the Tibetans, I am not discussing it here.

${ }^{14}$ See Mackerras, China's Ethnic Minorities; China's Minorities and China's Minority Cultures.

${ }^{15}$ Mackerras, 'People's Republic of China: Background Paper on the Situation of the Tibetan Population'.
} 


\section{Hong Kong, Macau and Singapore}

We now turn from Australia to the Asian component of this study. In fact, almost all the space will be given to Hong Kong. There is one scholar who has written extensively on Tibet in Macau, namely Professor Herbert Yee of the Macao Polytechnic Institute. However, although he writes bilingually, his major work on Tibet is in fact in Chinese and therefore not within the present paper's ambit. ${ }^{16}$

The National University of Singapore employs no Tibetologists as defined earlier in this article but quite a few world-ranking specialists on China, their fields ranging from medieval history to Chinese in Southeast Asia. In particular, the East Asian Institute has shown itself extremely productive of publications in all kinds of areas relating to contemporary China. Ethnic issues, including Tibet, are an area of interest, but papers and monographs exclusively about it are few. The newly founded journal East Asian Policy has done a good job of keeping abreast of developments in China, and there is one article dealing with the Tibet question. Its author Huang Jing has a PhD from Harvard University and is a visiting professor in the Lee Kuan Yew School of Public Policy. Mainly a specialist on Chinese politics and foreign relations, Tibet is peripheral to his main work. His paper in East Asian Policy argues for a change in the Chinese leadership’s thinking on Tibet. ${ }^{17}$

Hong Kong is pre-eminent in China for its diversity of traditions, almost entirely Chinese ethnically, but with a heavy dose of Western influence through the years of British colonialism. 'Free Tibet' activists hold some influence in public opinion, though not politically to anything like the extent obvious in a country like Australia. Of course the great majority of Hong Kong's scholars are

\footnotetext{
${ }^{16}$ Note Yee, 'Political Attitudes and Political Participation in Tibetan Regions'. In an obscure journal, it summarises in English some of the main work Yee has written in Chinese.

${ }^{17}$ Huang, 'The Tibet Issue'.
} 
Chinese, but there is also a significant Western minority who work in Hong Kong either temporarily or permanently.

Probably the main contributor to Tibet studies in Hong Kong's universities, at least in English, is Dr Barry Sautman of the Hong Kong University of Science and Technology. A Canadian and American by nationality, he has worked in Hong Kong for quite a few years and done extensive research on such issues as China's role in Africa. His research on Tibet tends to be contemporary, or uses history to cast light on contemporary times.

Sautman's works include a monograph that is too long to be an article but not long enough to count as a book, published by the University of Maryland School of Law, ${ }^{18}$ and a book in Chinese consisting of translations of his work so far, published by the Tibetology Press in Beijing. In addition, he has published a book in English and entirely about Tibet and edited jointly with another scholar. ${ }^{19}$ However, up to early 2010, he had not yet published a fully authored book focusing on Tibet in English.

Despite this, he is tremendously productive as a scholar and has published quite a few articles, including some very long ones. He does not know Tibetan and has no specialist knowledge of Tibetan culture, but balances this lack with profound understanding of world history and international law. He regards his main disciplines as law and political science, but insists on the importance of the relationship between Chinese and Tibetan politics and on the comparative approach, to which I'll be returning below. The significance of that is the ability to make relevant cross-cultural comparisons and contrasts that bear on the

\footnotetext{
${ }^{18}$ Sautman, 'All that Glitters is Not Gold'.

${ }^{19}$ Sautman and Dreyer, eds. Contemporary Tibet.
} 
international role of Tibet, on issues of national independence and the nature of the concept of nation.

In political terms, Sautman tends to be defensive of China, including both its claim to Tibet on historical and legal grounds and its main essential policies towards its ethnic minorities, especially the Tibetans. Because this is not a fashionable position in Western countries nowadays, he has become a controversial figure, and because he is so well informed and his research so thorough, he is often invited to represent pro-Chinese positions in forums dealing with Tibet.

We may take several of Sautman's articles that deal with specific and highly controversial debates. One of particular importance is the charge of 'cultural genocide’ levelled against China. No less a person than the Dalai Lama described China's actions and policies in Tibet in precisely such terms in a speech he made on 16 July 1996 to the British Parliament in Westminster: 'The destruction of cultural artefacts and traditions coupled with the mass influx of Chinese into Tibet amounts to cultural genocide'. ${ }^{20}$

Sautman defines the term 'cultural genocide' carefully, and discusses its history, including reference to the Tibetan exile understanding of the term. With a vast array of legal, political and historical material, he analyses whether the Chinese have in fact been guilty of cultural genocide in Tibet. His conclusion is that the concept of cultural genocide in Tibet 'is inapposite legally and empirically' and a disservice to 'the urgent struggle against destruction of peoples and their cultures'. ${ }^{21}$ He argues that what is proceeding in Tibet is 'cultural

\footnotetext{
20 'Address by His Holiness the Dalai Lama at the Palace of Westminster, LONDON July 16, 1996'.

${ }^{21}$ Sautman, “Cultural Genocide” and Tibet': 240. For an revised and updated version of this article, see also Sautman, 'Tibet and the (Mis-)Representation of Cultural Genocide’.
} 
change, not cultural genocide', mainly the result of Western modernity, mediated through China. 'Tibetans are not subjected to a concerted, state-backed effort to destroy their culture'. ${ }^{22}$

Besides cultural genocide, a common accusation against China, made first in 1984, is that its rule has led to the deaths of 1.2 million Tibetans. ${ }^{23}$ Again, Sautman has disputed this charge of 'demographic annihilation'. Noting that the Tibetan population increased by about 1 million in 1268 to about 2.5 million in 1950, he states that Tibetans more than doubled in number between the latter date and the early twenty-first century. This is in sharp contrast with what has happened in many colonial situations. According to Sautman, the charge against China is more in line with 'the émigré leaders' ideological construct of a colonial occupation' than with reality. ${ }^{24}$

Another issue of importance is the Dalai Lama and his proposals for 'genuine autonomy'. On the subject of the Dalai Lama himself, Sautman is extremely critical. For instance, he claims that amid support for non-violence, the Dalai Lama has regularly supported war conducted by his patrons the United States and India. ${ }^{25}$ On the subject of 'genuine autonomy' I referred above to an article on this subject that he wrote together with He Baogang, and, though he has written elsewhere in similar vein, ${ }^{26}$ there is no need to pursue the issue here.

A third issue that has aroused debate is economic inequality, the suggestion being that the Tibetans have suffered severe oppression causing great inequalities by comparison with the Han in labour, living standards and social status. In a wide-ranging study of various kinds of inequality in Tibet, he and Eng conclude

\footnotetext{
${ }^{22}$ Sautman, 'Tibet and the (Mis-)Representation of Cultural Genocide', 169.

${ }^{23}$ See details in Sautman, “'Demographic Annihilation” and Tibet', 237

${ }^{24}$ Sautman, “'Demographic Annihilation” and Tibet', 247.

${ }^{25}$ Sautman, 'Vegetarian Between Meals'.

${ }^{26}$ For instance, see Sautman, “Association, Federation and "Genuine” Autonomy’.
} 
that disparities are mainly urban versus rural and appear ethnic only because the Han are in practice much more thickly concentrated in the cities than in the countryside. 'As elsewhere in China, urbanites benefit disproportionately. In Tibet, the Han are urban, but so too is the "new Tibetan middle class.”, 27

Sautman has a grant to study Tibetan ethnic cadres in Tibet's development. He told me during our interview that he had collected a great deal of interview material on this topic as well as various other contemporary economic, social and other issues. However, he has not yet had time to write up into coherent and publishable form.

Another very important scholar of Tibet in Hong Kong is Professor Gerard A. Postiglione, an American who is director of the University of Hong Kong's Wah Ching Center of Research on Education in China. As this position suggests, his overwhelming research interest is in education, specifically the sociology of Chinese education, though he also writes on educational issues facing countries throughout the Asian region. He has published extensively on education in China, but most of his work has been on ethnic minority, specifically Tibetan, education. Postiglione differs from other scholars of Tibet in that he is in a professional school. He has been a sought-after consultant on education and poverty alleviation in China, for example on Tibetan education in Qinghai for the United Nations Development Programme, and was also a consultant to China’s State Education Commission's division of ethnic minority education, headed by a Tibetan. In this year-long capacity-building project, he came to understand first hand the educational challenges that China's officials have to face in ethnic autonomous regions. His edited book on ethnic minority education in China is the most widely

\footnotetext{
${ }^{27}$ Sautman and Eng, 'Tibet: Development for Whom?', 72.
} 
cited volume in the field thus $\operatorname{far}^{28}$ and is due to be published in Chinese by the Ethnic Press of Beijing. He has written numerous articles including about a dozen specifically about Tibet and the Tibetans. He usually focuses on gaps between policy and practices, school access, instructional quality, bilingual education, curriculum relevance, and school based management. Most of his fieldwork has been in rural and nomadic villages of Nyerong, Penam and Lhundrup counties.

His research results suggest that, while poverty has continued to affect school attendance rates in some areas, other factors also played a role, including household labour needs, the quality of teachers, the perceived value and relevance of schooling to community life and non-farm labour jobs. The most important measures for improved school participation rates were qualified teachers, curriculum relevance, household financial incentives, and the reduced employment of children in household labour.

Although he has learned some Tibetan, he works much more readily with Chinese sources. The cooperation of Tibetan colleagues has proved extremely beneficial to his work, especially his collaboration with Ben Jiao, an anthropologist who received his doctorate under the tutelage of Melvyn C. Goldstein at Case Western Reserve University and is deputy director of the Contemporary Tibetan Research Institute at the Tibet Academy of Social Sciences. ${ }^{29}$ Postiglione’s fieldwork methodology involves extensive interviewing and surveying, mostly carried out in Tibetan. His approach is generally appreciative of China's policy and practice in the field of ethnic education, but this does not prevent his reaching critical evaluations of the quality of education offered in schools and classrooms. For example, in an introductory paper to a

\footnotetext{
${ }^{28}$ Postiglione, ed., China's National Minority Education.

${ }^{29}$ For instance, see Postiglione, Jiao and Tsering, 'Tibetan Student Perspectives on Neidi Schools'.
} 
special issue of the journal Educational Review on Tibet and the Tibetans, he argues that the schooling experience among the Tibetans has produced mixed results, which so far have not been able to 'foster a harmonious multiculturalism that can sustain Tibet's social and economic development', a sympathetic but critical perspective that typifies his scholarship about schooling, not only on Tibet but globally. By this he means that while Tibet's long term educational challenge will be to make schools contribute directly to China's economic development and national unity, the best way to do that is to sustain the adaptive capacity of local Tibetan cultural vitality. ${ }^{30}$

He told me during our discussions on 13 March 2010 that he believes there is a special responsibility for scholars of education to do more than describe and analyse the education system; it is also helpful to China and the Tibetans for those committed to educational development to point out the obstacles to improved instructional quality that can foster critical and innovative thought, rather than merely praise the achievement of getting more Tibetans to attend school. He is also driven by the question of why Tibetans continue to underachieve in education. His next plan is to examine how China's promotion of mass higher education is affecting Tibetans’ job prospects, an area he sees as essential to continued stability in Tibet.

Finally, we can mention a scholar with an entirely different discipline orientation. This is Maggie Hui (Chinese name Hui Mei Kei), who is an Assistant professor in the School of Architecture, Faculty of Social Sciences, at the Chinese University of Hong Kong. Although trained in architecture largely in Australia, she did her $\mathrm{PhD}$ at the Chinese University of Hong Kong, her topic being Tibetan

\footnotetext{
${ }^{30}$ Postiglione, 'Making Tibetans in China', 3-4.
} 
monastic settlement and village architecture, with a perspective on religious spatial formation and transformation in everyday living. The focus on architecture and its relationship with Tibetan Buddhism and society adds an extremely valuable dimension to Tibetan studies in Hong Kong, given the significance of architecture for culture generally.

\section{Some General Discussion}

The following section offers some general comments on the approach to Tibetan studies adopted by some of the scholars discussed in this paper. Based largely on the interviews I undertook, it draws out some striking or important features of the scholarship discussed here.

\section{Approach, Point of Departure}

We begin with the point of departure of several of the main scholars on Tibet discussed here. In the interviews I found several very interesting and relevant differences over this matter.

I begin with the genuine Tibetologist John Powers:

Powers: I began with the study of Sanskrit Buddhism, but found that a lot of the texts I wanted to read only existed in Tibetan. So I decided I had to move to another program where I could learn Tibetan properly, as well as continue with Sanskrit. That's why I went to the University of Virginia, it was the only place that had a comprehensive Tibetan program where you could work with lamas.... My main intention was really to work primarily on classical philosophical texts ...

Mackerras: Would you say you were originally a historian of ideas?

Powers: Yes. And I think I still am. That's really what I'm doing. Many of the ideas I'm dealing with now are more contemporary ones, such as propaganda, including not just 
propaganda itself but the ideas that motivated them, that lay behind them. You have very different belief systems among the Tibetans and Chinese.

I got a very different, but to me equally valid, response from Barry Sautman. I don’t consider myself to be a Tibetologist, or a Tibet specialist. I am interested in the Tibet question as a species of political discourse. To understand how debate about the Tibet question has proceeded you have to understand many different aspects, economic, social, cultural and of course political aspects. .... I've tried to touch on quite a number of the important aspects in my work, but obviously there are so many that it is impossible to cover them all. In the main, what I've attempted to do in my own work is look at those questions that are debated most internationally and try to bring to them some kind of comparative perspective. With regard to any kind of controversial political question, you have to have some knowledge not only of the country or jurisdiction involved, but knowledge of the question elsewhere and on a global basis. You can’t understand how society is developing in one place without some knowledge of how it is developing elsewhere. The major failing of studies of the Tibet question thus far is the almost complete lack of comparative perspective.

Several of the scholars discussed here have taken an interest in various China's ethnic groups. Postiglione’s study of comparative education has led him to work on minorities in China, including the Dongxiang, Mongols, and Yao, and other parts of the world. Hillman has focused both on Chinese and Indonesian ethnic issues. Both Postiglione and Hillman can claim to be comparative in that sense. But Sautman is alone in making detailed comparisons in law, policy, politics and other aspects of the situation of ethnic minorities in many parts of the world and covering numerous different periods. This emphasis on the comparative perspective I believe to be extraordinarily useful and productive. 
In the interview I held with him on 10 October 2009 Ben Hillman also stressed that he did not consider himself 'to be a Tibetologist or a Tibetan expert' and that his interest in Tibet was really 'peripheral' to his interest in politics and social and political change in China, but with an emphasis on ethnic minorities policy. Susette Cooke came from a similar point of view. She told me: 'I came to be interested in Tibet through a lens of having been interested in China'. I would put myself in the same category. My original interest in Tibet developed through study of Chinese history and contemporary China. I carried out research on the Uighur state (744-840), mainly through Chinese sources, and returned to an interest in China’s ethnic minorities much later.

For Gerard Postiglione, the point of departure is the sociology of comparative education. He is himself of Italian background but brought up in New York City. He has lived in Hong -Kong for decades, but also worked for several years in Beijing. His interest in Tibet originated from his background as an Italian-American growing up in a multiethnic city and observing the ethnic intergroup processes there. But he later studied education in Southeast Asia, Mongolia, and various parts of China, especially the city that became his home, namely Hong Kong. Tibetan education is central to his interests, but the origin comes not from China but elsewhere.

\section{Methodology, Interviewing}

The study of documents is an important part of the methodology of all the Tibet scholars considered here. On the other hand, the main language of primary sources tends to vary according to the point of departure. Sonam Thakchoe and Templeman use Tibetan but not Chinese, Powers emphasizes Tibetan but also 
knows Chinese, Stevenson uses Tibetan but works more readily in Chinese, Hillman and Postiglione have learned some Tibetan and are deeply versed in Chinese, while among the other scholars, He, Cooke, Sautman, and me, knowledge of Tibetan is sparse or non-existent.

Most of the scholars discussed here rely on fieldwork and interviewing. Stevenson has lived in Huangnan over extensive periods, gathering material through interviews and in other ways covering different periods and thus gaining insight into how the situation has developed over time. In Diqing Prefecture, Yunnan Province, Hillman was able to 'talk to hundreds if not thousands of people’, including 'ethnic Tibetans, non-Tibetans, government officials, members of the religious establishment, ordinary farmers, workers, businesspeople', giving him a privileged insight into the Tibetan situation in one particular locality. Cooke has done fieldwork in many of the Tibetan areas beginning in 1980. She lived in the Tibet Autonomous Region for most of 1993, but her long-term familiarity with all the Tibetan areas of China gives her an unusual perspective covering the period from 1980 to 2010. She told me, 'my stays in the Tibetan areas have been incremental, and that meant all the Tibetan areas, not just the Tibet Autonomous Region. I didn’t focus on one Tibetan area more than another'. Sautman has collected enormous amounts of interview and also survey material in the TAR and Dulan County in Qinghai. Teams of Tibetans conducted the interviews, using Tibetan language, but they were then transcribed into Chinese. Postiglione has interviewed widely in villages in the Tibetan Autonomous Region for his research, but has also interviewed in Tibetan areas of Gansu and Qinghai for his consulting work. 


\section{Attempting to Solve Practical Problems Through Tibet Studies}

The study of Tibet is primarily an academic pursuit and using it to help one side or another lays the scholar open to the accusation of the charge of bias. However, in the interviews I did with scholars I found everybody concerned to improve the situation for Tibetans and to reduce conflict. I instance four particular cases where the scholars of Tibet specifically aimed to help Tibetans or to help solve the Tibetan question. They illustrate rather different approaches, but have in common the desire to assist Tibetan society and development, assuming the context of remaining within China.

Ben Hillman has been at the forefront of setting up a pilot school in Diqing, specifically targetting young Tibetans and improving their employability. Its courses last three months and teach skills like basic communication and computing, deportment, and how to present a curriculum vitae document or do job interviews. What drove Hillman to set up this school was the belief, to which his own research had led him, that discrepancies between Han and Tibetan in economic terms resulted not from any formal discrimination, but from Tibetans' lack of job skills and discipline. Even Tibetan employers prefer to hire Han over Tibetans, because experience suggests the former are more reliable in showing up for work and likely to give better service. Meanwhile, Tibetan youth unemployment spawns serious social problems, such as gambling, unwanted pregnancies in unmarried women and furious resentment from people who see brilliant success among Han immigrants into what they regard as their own territory, while they themselves are left behind. The five-year record of the school, the only one of its kind in Western China, has been excellent, almost all students having found a suitable job. With new funding from USAID over the 
next five years, Hillman is currently trying to encourage educational authorities, especially at central level, to incorporate some of this experience in its policies and to make the pilot scheme more permanent.

My second example illustrating the practical approach is Professor $\mathrm{He}$ Baogang, who not only undertakes extensive research on Tibetan political issues but also tries to promote dialogue among the conflicting parties aimed at promoting trust and leading to a solution. A very recent article in this category is 'Deliberative Approach toward the Tibet Autonomy Issue, Promoting Mutual Trust through Dialogue', published in Asian Survey. The deliberative approach stresses trying to persuade people with fixed ideas to overcome prejudices and see merit in the viewpoints of others. This is in sharp contrast to debate, which tries to persuade others to a particular point of view. He undertook such a process of deliberation in his own University, Deakin University, over three days in November 2008, which he claims as a good beginning. Although his evaluation of the forum was mixed, he was quite clear that a citizen-initiated deliberative forum was more effective than a state-initiated one, especially one trying to persuade people to a particular viewpoint. The following exchange is from the 23 November 2009 Deakin University workshop.

He Baogang: It's difficult for the Chinese side to take the deliberative approach seriously. But at the same time we did find in other political contexts, local government has tried deliberative dialogue more and more to solve daily problems. In order to avoid conflict, this kind of practice has become more and more widespread. One day the Chinese government will have to try this method to deal with the ethnicity issue.

Mackerras: I agree with you entirely about that. 
He: How to influence state power is an issue. In my paper I discuss John Dryzek’s ideas. ${ }^{31}$ He believes deliberation should be semidetached from state power. If it is fully attached to the government, the quality of deliberation is compromised....

Deliberation should be open and equal; it should debate merits, and come up with a good idea. People-to-people deliberation is the best way to go.

Mackerras: What do you mean by 'semi-detachment'?

He: If it is really close to state power, then dialogue breaks down. There must be some links with the state, but not too direct. A good example of semidetached deliberative dialogue took place over [the ancient Korean kingdom of] Gaojuli [which the Chinese state regards as Chinese because it mostly covered territory now in China, but which the Korean state regards as Korean because it was culturally entirely Korean]. When both the Korean and Chinese states sponsored the dialogue, discussion was deadlocked and paralysed, and flew off in different directions. But when semi-official historians and scholars held deliberation, they did produce a textbook that took up the issues.

Leibold: But I believe nobody’s using it?

He: It's being used as a supplementary text in Korea and Japan. I followed the online debate in China, which I found very impressive. Some Chinese students have read it and praised it for opening their mind. It does have positive effects on people. In terms of numbers sold, it's been extremely impressive. That's what I mean by semi-detachment. If the deliberation is state-dominated, it will get nowhere. You can only get a result if you have some detachment from the state. Finally, it will penetrate state power.

Mackerras: Students influenced by it might eventually themselves become part of the government.

\footnotetext{
${ }^{31}$ He's reference to his own paper is to 'Deliberative Approach to the Tibet Autonomy Issue'. His reference to Dryzek is to 'Deliberative Democracy in Divided Societies', p. 218, where the argument is for 'a power-sharing state with attenuated sovereignty and a more engaged deliberative politics in a public sphere that is semidetached from the state and situated transnationally'.
} 
He: This is a long process, but I think this deliberative way is the best way forward, and will eventually produce good results.

The last two of my case studies of what we can call 'the practical approach' are both from Hong Kong. Maggie Hui has used her architectural skills to assist Tibetans by surveying Tibetan houses and monasteries in Western China. Her work has been voluntary and in the service of a non-government organization. The final example is Gerard Postiglione. Like He Baogang, he emphasizes trying to solve specific questions, but on education among the Tibetans. He aims his work at pointing out challenges and helping to find solutions to serious problems education in Tibet faces. He told me during our interview:

I am working in a faculty of education, a professional faculty. So I have a responsibility to solve educational problems .... I feel I have a responsibility in the following kinds of areas when I shape my methodology. For example, is education useful, why do families support education, what are the obstacles to improving education, what kind of schooling is best suited for the environments that Tibetan children grow up in, do Tibetan children have stages of development different from other groups?... My objective should often be, what can or should be done to improve education? As scholars we have critical points of view in our work, that's what makes us scholars.... My critical points of view are often focused on this one question of how can we make the educational experience more relevant for the development of the people, not only their livelihood, their standard of living, but also the vitality of their culture of their social groups, of their society..... In the end it's all about the ability to learn, the ability to adapt knowledge to the lives that people live and the value of education and how families participate in the education of their children. These are the issues which to me are important. 
He also stressed during our interview that the aims of education include raising the quality of leadership among the Tibetans, giving them entrepreneurial skills that will help them adapt to the modern world and to developments in China. Believing that education is important in shaping culture, he is also keen to preserve Tibetan culture and believes this quite possible within the current context.

\section{Political Viewpoints}

From the start it was my intention to de-emphasize political approach to contemporary Tibet within China on the grounds that this was divisive. Several of the scholars I interviewed, such as Postiglione and Hillman, made clear that their wish to assist the Tibetans assumed the context that the Tibetan areas are part of China, which means that China shares in any assistance offered to Tibetans. In the Deakin University workshop, the general direction was one that promoted dialogue with a view to lessening conflict, although participants generally recognized how divided the study of Tibet has become and the issue of polarization arose several times.

Although all scholars I interviewed favoured dialogue either implicitly or explicitly and were happy for all points of view to get a hearing, some emphasized harmony more than others. John Powers was among those who appeared clear that it was neither possible nor useful to ignore the extent of polarization in the Tibet issue. However hard one tries to be objective and/or neutral, a general tenor of scholarship will favour one side or the other, and very good scholars may find themselves courted by representatives either of the Chinese or the TGIE. 
Powers: You inevitably get drawn into political matters. You just can’t avoid it. Also, it’s something important in getting grants. I can't get grants for my classical work, but I do get grants to do work on contemporary issues relating to Tibet. Mackerras: I agree it's a very divided field, but I don’t want to emphasize that. I’m not going to begin with the position that this scholar is pro-Dalai Lama, that one proChina, or whatever. I don't want to begin from that point of view.

Powers: It's not even necessarily along those lines. The polarization is more between people who are pursuing academic studies and those who are ideologues, I think. You have people who pursue things purely on an ideological front, usually following either one side or the other, but more commonly the Tibetan side. And then you have others, like myself, who are taking an academic approach. I have my own points of view and draw my own conclusions, but what I publish is based on evidence and things that I can prove or establish through the evidence that I gather.... I find that often both sides get offended by what I do.

Although Barry Sautman accepts Powers’s opinion that Tibet studies are polarized, he sees the syndrome of views represented by the Dalai Lama and the TGIE as far too dominant in the West, and especially North America. His experience is that views critical of the Dalai Lama or defensive of Chinese positions are very difficult to get published in Western academic outlets, however scholarly they may be. He has found 'what can only be described as political bigotry' on the Tibet issue to be very widespread in the United States, with many 'fanatics'. Although he has plenty of criticisms to make of the Chinese performance, his emphasis on the comparative perspective has led him to the position that many actions and policies for which the Chinese suffer condemnation actually show them as not so bad or even commendable in worldwide terms. 
On the subject of outside influence, a matter that was extremely controversial after the 2008 disturbances because the Chinese media put all the blame on 'the Dalai clique’, my interviewees put forward divergent positions. Talking of what might happen when the $14^{\text {th }}$ Dalai Lama died, Mark Stevenson said that any popular uprising would probably be more or less spontaneous and the result of 'a popular expression of trauma that's been building up in the twentieth century'. He continued:

I've had ongoing contact now with Rebkong [Huangnan] for close to twenty years. While there are a lot of people in touch with things that are happening outside China, my feeling is that it doesn't take very much, in a sense, to mobilize sentiment and it's not something that's being directed.

On the other hand, Sautman puts weight on the way outside forces behave:

The Tibetan service of Radio Free Asia, The Voice of America, and The Voice of Tibet, which is sponsored by the Norwegian government, are broadcasts that go on constantly, every bit of which is negative about China's policies in Tibet. To say that this has no effect at all on the way people act I think is extremely naive. Why would people abroad be investing huge amounts of time and effort into something that has no effect? They would give up after a while.

The emphases of the two scholars are clearly very different. Yet Stevenson is talking about one specific place, while Sautman's comments are much more global, which means that the two views are not actually in contradiction. 


\section{Conclusion and Evaluation}

This account makes no pretence at being comprehensive. However, a few tentative conclusions may follow from the material in this article.

It is obvious that there is a spectrum of views over the Tibet question and the political situation there. The immense divide in Tibet studies that is so evident in the United States and Europe is to some extent obvious also in Australia. But it is probably not so pronounced. The 'Tibet lobby’ certainly has its counterparts in Australia, but its grip is much less powerful. And with the rise of PRC influence for various reasons, this impact may be even less significant in Singapore and Hong Kong.

There are various categories of Tibet studies. The kind of Tibetology that places full weight on knowledge of the Tibetan language should be promoted and respected. However, in the countries and region considered here, Tibet studies are largely viewed as a subcategory of China studies or of discipline studies. Tibet is part of China now and the international community recognizes it as such. And an anthropologist or political scientist can take up the study of Tibet and the Tibetans as well as of another people. Comparative studies have become very widespread in many countries for almost all peoples and nationalities. And it is highly desirable that they should be applied also to Tibet.

However, if one considers what this implies in organizational terms, the situation is very unclear. China studies conferences in Australia rarely have panels exclusively on Tibet. The one noted earlier as having taken place in 2008 was actually at an Asian studies conference, not a China studies one. Nobody will deny that Tibet is in Asia. Considering departmental or administrative affiliation, 
we find that few of the people considered above are actually in China studies departments.

In evaluating Tibet studies in Australia, we can note that several of the main scholars are immigrants, for instance Powers from the U.S., He from China and Thakchoe, a Tibetan from India. However, what is perhaps striking is that there are quite a few who are not immigrants, such as Stevenson, Hillman, Cooke and myself. In a way, Tibet studies in Australia reflect the multiculturalism that the country regards as among its hallmarks.

A reasonably new trend exemplified by several of the individuals mentioned in this article is a body of scholars from China now teaching in the countries and region discussed here, who do not support Tibetan independence, but also remain critical of Chinese government positions. Some of them, such as He Baogang, develop independent analysis on policy issues, with a view to solving problems. Their influence could be growing among Chinese, including those in China itself.

Neither Australia nor Hong Kong can compete with the United States, India, or several other countries in terms of Tibet studies. One of the items on the agenda of the Deakin University workshop was how to promote Tibet studies. This is a cause that I fully support. The study of Tibet is a major way of promoting knowledge and understanding about Tibet, and ignorance is itself the most important source of prejudice.

\section{References}

Cooke, Susette, 'Becoming and Unbecoming Tu: Nation, Nationality and Exilic Agency in the People’s Republic of China'. In Exile Cultures, Misplaced 
Identities, ed. Paul Allatson and Jo McCormack. Amsterdam, New York: Editions Rodopi, B.V., 2008, pp. 33-56.

Cooke, Susette [published under the name John Kransky]. 'Central Lhasa and Migration: Economic Development and Social Consequences’, Provincial China 2 (October 1996): 16-44.

Cooke, Susette. 'Merging Tibetan Culture into the Chinese Economic Fast Lane', China Perspectives 50 (November-December 2003): 42-55.

Cooke, Susette. “"To Struggle for Freedom is Our Responsibility”, Tibetan Nuns in the Chinese State'. In Women, Activism and Social Change, ed. Maja Mikula. London and New York: Routledge, 2005, pp. 117-35.

Dalai Lama, ‘Address by His Holiness the Dalai Lama at the Palace of Westminster, LONDON July 16, 1996’, http://hhdl.dharmakara.net/westminster.html, accessed 22 September 2009.

Dryzek, John S. 'Deliberative Democracy in Divided Societies: Alternatives to Agonism and Analgesia', Political Theory 33, no. 2 (April 2005): 218-42. He, Baogang. 'Deliberative Approach to the Tibet Autonomy Issue, Promoting Mutual Trust through Dialogue', Asian Survey 50, no. 4 (July/August 2010): 709-34.

He, Baogang. 'Minority Rights with Chinese Characteristics'. In Multiculturalism in Asia, ed. Will Kymlicka and Baogang He, New York: Oxford University Press, 2005, pp. 56-79.

He, Baogang. Rural Democracy in China. New York: Palgrave Macmillan, 2007. He, Baogang. ‘The Dalai Lama’s Autonomy Proposal: A One-Side Wish?’. In Contemporary Tibet: Politics, Development and Society in a Disputed 
Region, ed. Barry Sautman and June Teufel Dreyer, Armonk, N.Y.: M.E. Sharpe, 2006, pp. 67-84.

He, Baogang. The Democratization of China. New York and London: Routledge, 1996.

He, Baogang. The Democratic Implications of Civil Society in China.

Basingstoke: Macmillan, New York: St. Martin, 1997.

He, Baogang, and Barry Sautman. 'The Politics of the Dalai Lama’s New

Initiative for Autonomy (1)’. Pacific Affairs 78, no. 4 (Winter 2005-Spring 2006): 601-29.

Hillman, Ben. 'Monasticism and the Local State: Autonomy and Authority in a Tibetan Prefecture’. The China Journal 54 (July 2005): 22-52.

Hillman, Ben. 'Money Can't Buy Tibetans' Love’, Far Eastern Economic Review 171, no. 3 (April 2008): 8-16.

Huang Jing,. 'The Tibet Issue: An Impasse of Entrapment?'. East Asian Policy 1, no. 3 (July/September 2009): 23-31.

Mackerras, Colin. 'The Australia-China Relations: A Partnership of Equals?'. In Re-orienting Australia-China Relations 1972 to the Present, ed. Nicholas Thomas. Aldershot: Ashgate, 2004, pp. 15-33.

Mackerras, Colin. China’s Ethnic Minorities and Globalisation, London: RoutledgeCurzon, 2003.

Mackerras, Colin. China's Minorities: Integration and Modernization in the Twentieth Century. Hong Kong: Oxford University Press, Hong Kong, 1994.

Mackerras, Colin. China’s Minority Cultures: Identities and Integration Since 1912. Melbourne: Longman Australia, New York: St Martin’s Press, New York, 1995. 
Mackerras, Colin. 'People’s Republic of China: Background Paper on the Situation of the Tibetan Population', Writenet Independent Analysis, A Writenet Report commissioned by the United Nations High Commissioner for Refugees, Protection Information Section (DIP), web publication, February 2005.

Postiglione, Gerard A., ed., China’s National Minority Education, Culture, Schooling, and Development, New York and London: Falmer Press, 1999. Postiglione, Gerard A. 'Making Tibetans in China: The Educational Challenges of Harmonious Multilculturalism’. Educational Review 60, no. 1 (February 2008): 1-20.

Postiglone, Gerard, Ben Jiao and Melvyn C. Goldstein, 'Education in the Tibetan Autonomous Region: Policies and Practices in Rural and Nomadic Communities'. In UnderstandingChina's Education Reform: Creating Cross Cultural Knowledge, Pedagogies and Dialogue. London and New York: Routledge, forthcoming.

Postiglione, Gerard A., Ben Jiao and Ngawang Tsering, ‘Tibetan Student Perspectives on Neidi Schools'. In Affirmative Action in China and the U.S., A Dialogue on Inequality and Minority Education, ed. Minglang Zhou and Ann Maxwell Hill. New York: Palgrave Macmillan, 2009, pp. 127-42.

Powers, John. History as Propaganda, Tibetan Exiles versus the People's Republic of China. New York: Oxford University Press, 2004. Powers, John. Introduction to Tibetan Buddhism. Ithaca, N.Y.: Snow Lion Publications, 1995. 
Sautman, Barry. 'All that Glitters is Not Gold. Tibet as a Pseudo-State. Maryland Series in Contemporary Asian Studies, No. 3. School of Law, Baltimore: University of Maryland, 2009.

Sautman, Barry. 'Association, Federation and “Genuine” Autonomy: The Dalai Lama’s Proposals and Tibet Independence'. China Information 14, no. 2 (2000): 31-91.

Sautman, Barry. ““Cultural Genocide” and Tibet’. Texas International Law Journal 38, no. 173 (2003): 173-247.

Sautman, Barry. ““Demographic Annihilation” and Tibet’. In Contemporary Tibet, Politics, Development, and Society in a Disputed Region, ed. Barry Sautman and June Teufel Dreyer. Armonk, N.Y.: M.E. Sharpe, 2006, pp. 230-57.

Sautman, Barry. 'Tibet and the (Mis-)Representation of Cultural Genocide’. In Cultural Genocide and Asian State Peripheries, ed. Barry Sautman. New York: Palgrave Macmillan, 2006, pp. 165-272.

Sautman, Barry. 'Vegetarian between Meals: The Dalai Lama, War and Violence'. Positions, East Asia Cultures Critique forthcoming.

Sautman, Barry and Dreyer, June Teufel, eds. Contemporary Tibet : Politics, Development, and Society in a Disputed Region. Armonk, N.Y.: M.E. Sharpe, 2006.

Sautman, Barry, and Irene Eng. 'Tibet: Development for Whom?'. China Information 15, no. 2 (2001): 20-74.

Stevenson, Mark. Many Paths: Searching for Old Tibet in New China. South Melbourne: Lothian, 2005. 
Thakchoe, Sonam. 'Status of Conventional Truth in Tsong Khapa's Mādhyamika Philosophy’. Contemporary Buddhism, An Interdisciplinary Journal 8, no. 1 (May 2007): 31-47.

Thakchoe, Sonam. The Two Truths Debate: Tsongkhapa and Gorampa on the Middle Way. Boston: Wisdom Publications, 2007.

Thakchoe, Sonam. 'Transcendental Knowledge in Tibetan Mādhyamika Epistempology’. Contemporary Buddhism, An Interdisciplinary Journal 6, no. 2 (November 2005): 131-52.

Yee, Herbert.

'Political Attitudes and Political Participation in Tibetan Regions: A Report on Field Research in Lhasa, Shannan, Gannan and Ganzi,' Asian Thought and Society 25, no. 74 (May-August 2000): 137-56.

\section{Interviews}

Cooke, Susette, of the University of Technology, Sydney, 9 October 2009,

Hillman, Ben, Australian National University, 10 October 2009.

Postiglione, Gerard, The University of Hong Kong, 13 March 2010.

Powers, John, Australian National University, 11 December 2009.

Roche, Gerald, Griffith University, 18 January 2010.

Sautman, Barry, University of Science and Technology of Hong Kong, 16 October 2009.

Workshop, held at Deakin University, Melbourne, on 23 November 2009. Participants included He Baogang, Deakin University, Melbourne; James Leibold, La Trobe University, Melbourne; Mark Stephenson, Victoria University, Melbourne; and Gillian Tan, University of Melbourne. 